\title{
A PSICOLOGIA DA APRENDIZAGEM E A LICENCIATURA EM MATEMÁTICA: APROXIMAÇÕES E DISTANCIAMENTOS NESSA RELAÇÃO
}

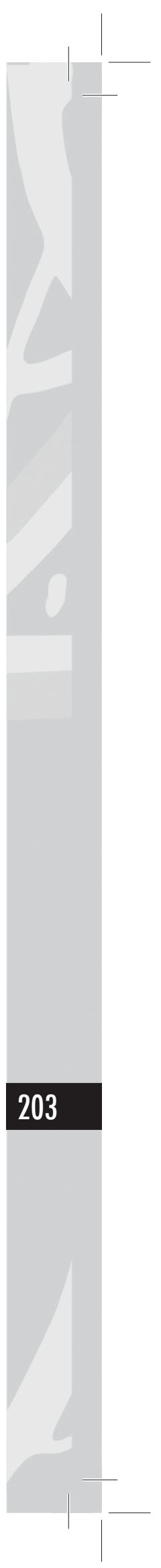

Resumo: Este estudo surgiu a partir das inquietações vivenciadas na disciplina Psicologia da Aprendizagem, ministrada nas turmas do Curso de Licenciatura em Matemática, e teve como objetivo investigar a percepção conceitual dos professores em formação inicial em relação à disciplina, na perspectiva de identificar as aproximações $e$ os distanciamentos que existem entre a disciplina e a curso. A investigação foi realizada junto a 21 alunos, selecionados nas três turmas em que ministramos a disciplina. As informações foram constituídas via questionário com questões semiestruturadas. As respostas dadas aos questionamentos - Percepção conceitual dos professores em formação sobre a Psicologia da Aprendizagem. A relação/identidade dos Professores em formação com a disciplina Psicologia da Aprendizagem. Distanciamentos e Aproximações entre a Psicologia da Aprendizagem

1 Mestre e Doutoranda do Programa de Pós-Graduação em Educação em Ciências e Matemática -PPGCEM/REAMEC da Universidade Federal do Pará - UFPA. Professora Assistente da Faculdade de Matemática da Universidade Federal do Pará, do Campus Universitário de Castanhal.

2 Professor do Programa de Pós-Graduação em Educação em Ciências e Matemática - PPGCEM da Universidade Federal do Pará - UFPA. 


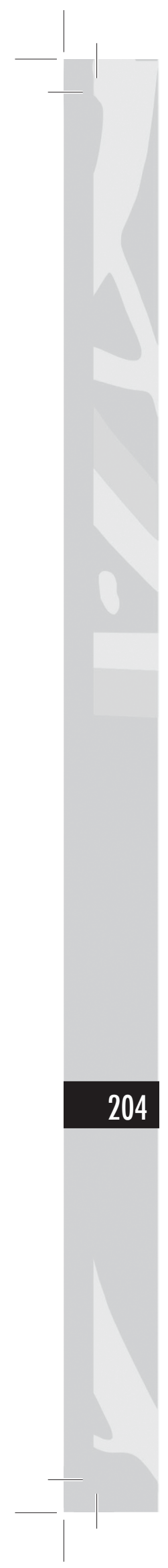

e a Licenciatura em Matemática - serviram de eixos de análise. As análises foram baseadas na metodologia da Análise Textual Discursiva, defendida por Roque Moraes. Os resultados apontam que nas percepções desses professores em formação, existem distanciamentos e aproximações na relação entre Psicologia da Aprendizagem e a Licenciatura em Matemática.

Palavras-chave: Psicologia. Aprendizagem. Percepção. Aproximações. Distanciamentos.

Abstract: This study arose from concerns experienced in the discipline of Psychology Learning, taught classes in the Bachelor of Mathematics and aimed to investigate the conceptual perception of teachers in initial training in relation to the discipline, in order to identify the similarities and distances that exists between the discipline and course. The investigation was conducted with 21 students, selected the three classes we teach in the discipline. The information was made via semi-structured questionnaire with questions. The answers given to the questions - conceptual perception of teachers in training on the Psychology of Learning. The relationship / identity of Teachers in training with the discipline of Psychology Learning. Distances and approaches between the Psychology of Learning in Mathematics and served as axes of analysis. The analysis were based on the methodology of Textual Discourse Analysis, defended by Roque Moraes. The results show that in perceptions of these teachers in training, there are distances and approximations in the relationship between Psychology and Learning in Mathematics.

Keywords: Psychology. Learning. Perception. Approaches. Distances.

Introdução

$\mathrm{O}$ binômio ensinar e aprender são elementos significativos e presentes na construção do conhecimento. E a relação que se estabelece entre os dois aspectos é reforçada por determinadas teorias, que nos levam a indagar sobre $o$ que ensinamos, como ensinamos e para que ensinamos. Essas indagações estão diretamente relacionadas à figura do educador e ao ambiente de formação. 
Educadores de todos os níveis vivem em seus ambientes de práticas as angústias de não conseguirem compreender os porquês do insucesso escolar de um número significativo de alunos que, a cada final de um ano letivo, não conseguem aprovação para as séries subsequentes. No ambiente escolar, vários são os elementos (culturais, sociais, políticos, econômicos) que se configuram e que contribuem de forma significativa para que esses resultados sejam encontrados na escola. No entanto, esses por si só não dão conta de explicar o quadro de reprovação, repetência, evasão, dificuldades de aprendizagem, etc. Outro elemento se faz presente neste cenário - a formação inicial de professores para a Educação Básica.

Durante a formação inicial em cursos de licenciaturas, professores em formação estudam, nos primeiros três anos do curso, as disciplinas específicas de área e, no último ano, as disciplinas pedagógicas, que, a princípio, se tem a ideia de que essas disciplinas darão conta de preparar o professor o suficiente para que se torne capaz de mediar de forma eficaz as situações surgidas no ambiente escolar.

No entanto, as disciplinas pedagógicas, dentre elas a Psicologia da Aprendizagem, não devem ser vistas como as 'resolvedoras' dos problemas que se desenham na/em sala de aula. A percepção que se deve ter sobre essas disciplinas é que essas servirão de base para que os professores em formação possam ter uma proximidade com as teorias estudadas e que a integração desses conhecimentos permitirá que os problemas de ensino-aprendizagem que estão situados na/em sala de aula sejam compreendidos e mediados pelos professores.

Com base nesse pressuposto e considerando a relevância do estudo situado em nossa prática docente, realizamos a pesquisa em três turmas do Curso de Licenciatura Plena em Matemática, na perspectiva de responder as seguintes indagações: Qual a percepção sobre a Psicologia da Aprendizagem desses professores em formação? Como os professores em formação na área da Matemática se relacionam/identificam com a disciplina Psicologia da Aprendizagem? Como ocorre o processo de distanciamento e aproximação entre a Psicologia da Aprendizagem e a Licenciatura

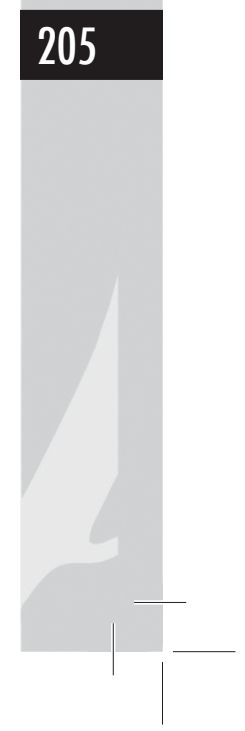




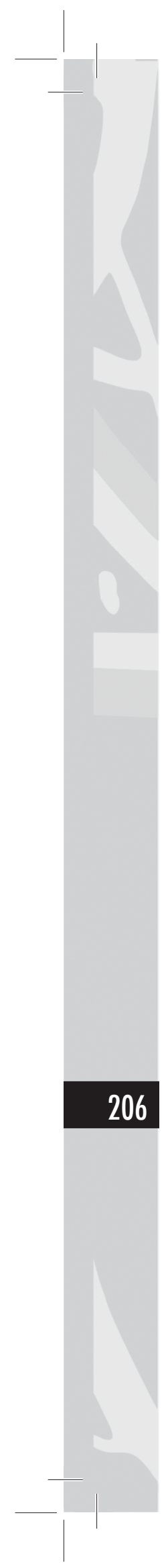

em Matemática? Esses questionamentos surgiram a partir das aulas trabalhadas na disciplina Psicologia da Aprendizagem nas referidas turmas.

A disciplina Psicologia da Aprendizagem para o curso de Licenciatura em Matemática do universo investigado é ofertada no $5^{\circ}$ Semestre do curso, e, do total de 74 professores em formação das três turmas em que trabalhamos com a disciplina, 25 estão cursando o $7^{\circ}$ Semestre e 49 estão finalizando o $8^{\circ}$ semestre do curso. Na intenção de aplicar os questionários com questões semiestruturadas para a constituição das informações a um grupo menor, houve a necessidade de criar critérios para selecionar os sujeitos que participaram do estudo.

Assim, estabelecemos como critério selecionar somente os professores em formação que manifestaram interesse em desenvolver seus trabalhos de conclusão de curso na área da Educação Matemática, após terem cursado a disciplina. A partir desse critério, os sujeitos foram selecionados da seguinte maneira: da turma de 2009/Extensivo de 25 professores em formação, seis foram selecionados por terem optado em fazer o Trabalho de Conclusão de Curso na Educação Matemática. Da turma 2009/ Intensivo de 24 professores em formação, seis fizeram a opção, e, da turma 2010/Extensivo de 25 professores em formação, nove fizeram a opção. A partir desse critério, selecionamos 21 sujeitos que correspondem a $29 \%$ do total de professores em formação. Após o processo de seleção, aplicamos os questionários e, a partir das respostas as questões de investigação, agrupamos as informações, considerando cada questão como um eixo de análise. Considerando que esta pesquisa é de abordagem qualitativa, elegemos a metodologia da Analise Textual Discursiva para realizar a análise, pois essa nos permite trabalhar com os textos que compõem o corpus da análise, produzidos especialmente para a pesquisa e que

[...] não carregam um significado a ser apenas identificado; são significantes exigindo que o leitor ou pesquisador construa significados com base em suas teorias e pontos de vista. Isso exige que o pesquisador em 
seu trabalho se assuma como autor das interpretações que constrói dos textos que analisa. Naturalmente nesse exercício hermenêutico de interpretação é preciso ter sempre em mente o outro pólo, o autor do texto original. (MORAES, 2003, p. 194)

Na Analise Textual Discursiva, optamos em trabalhar com o método indutivo que possibilita eleger categorias com base nas informações constituídas, permitindo ao pesquisador organizar, por um processo de comparação entre as unidades de análise, um conjunto de elementos semelhantes, geralmente com base em seu conhecimento tácito (LINCOLN e GUBA, 1985). O método traz em si a subjetividade e foca na qualidade, na ideia de construção, na abertura ao novo que Boaventura Santos (1996) denomina paradigma emergente (MORAES, 2003).

A partir da definição do método, transformamos as questões norteadoras da investigação em unidades definiram eixos de análise assim constituídos: Eixo de Análise 1 Percepção dos professores em formação sobre a Psicologia da Aprendizagem. Eixo de Análise 2 - A relação/identidade dos professores em formação com a disciplina Psicologia da Aprendizagem. Eixo de Análise 3 - Distanciamentos e Aproximações entre a Psicologia da Aprendizagem e a Licenciatura em Matemática.

Fizemos então a interpretação (MORAES, 1999) do conjunto de significados expressos nos eixos de análise definidos, embasadas em teorias que fundamentaram as discussões. Vale ressaltar que a análise textual discursiva é uma interpretação pessoal por parte do pesquisador com relação à percepção que tem das informações constituídas. Desta forma, a organização deste artigo compreende as fundamentações, as análises e as interpretações das ideias aqui constituídas. Para fundamentar as questões aqui abordadas e entender melhor as relações entre a Psicologia da Aprendizagem e a Licenciatura em Matemática, consideramos relevante, ainda que de forma sucinta, fazer uma breve contextualização da Psicologia como uma ciência que contribuiu de forma significativa para a Educação. 


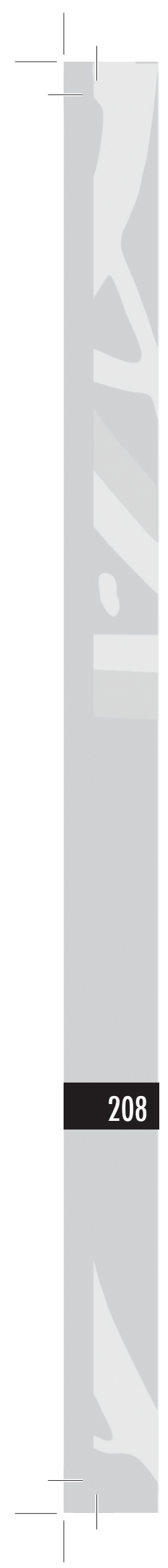

A Psicologia como ciência distanciada das demais ciências surge com as pesquisas realizadas na Universidade de Leipzig pelo pesquisador alemão Winhelm Wundt (1832-1920), que em 1879 funda o primeiro laboratório de Psicologia Experimental (CARVALHO, 2005), considerado um marco para o nascimento da Psicologia como ciência.Após estudos realizados sobre as outras ciências, apontou pontos significativos sobre o objeto de estudo da Psicologia - a experiência imediata e as sensações sem interpretações são formadoras de nossa consciência.

Para avançar como ciência, a Psicologia se vincula a outras áreas do conhecimento que resulta em teorias ligadas às questões educacionais, em que se destacam as contribuições de Pavlov no que se refere à aprendizagem, com experimentos realizados com animais, a partir do processo de condicionamento por meio de estímulos externos. Esses resultados com auxílio das ciências comparadas foram trazidos posteriormente, para o campo dos seres humanos.

Com o avanço da Psicologia, outras contribuições surgem para a compreensão do homem, e um dos maiores vultos da Psicologia foi Sigmund Freud, que defendia o inconsciente como a sede máxima dos conflitos intrapsíquicos, como forma de compreender o conflito mediado pelo Ego entre o Id e o Superego. Apesar de não ter dedicado suas experiências para compreender as questões educacionais,

[...] é compreensível que as investigações da vida sexual das crianças e de seu desenvolvimento psicológico tenham atraído a atenção de educadores e lhes mostrado seu trabalho sob nova luz. (FREUD apud KUPFER, 1989, p. 12).

As teorias de Freud são aplicadas em grande parte para compreender as situações surgidas no ambiente escolar, especialmente no que se refere às dificuldades de aprendizagem que estão presentes nas salas de aulas, que dependendo de quem a conduz, pode tornar essa aprendizagem mais ou menos prazerosa. 
Em se tratando das teorias que discutem a aprendizagem, destacamos a contribuição de Carl Rogers, que defendia o ensino centrado na perspectiva do aluno e que aprendemos aquilo que nos é significativo. Apesar de em grande parte se valorizar o aspecto psicológico na compreensão do homem e dos problemas de aprendizagem, outro aspecto deve ser considerado nesse contexto: $\mathrm{o}$ aspecto social que se constrói em diferentes momentos históricos, pois vivemos em meio a diversas concepções de sujeito e de sociedade, bem como de elementos que transformam tanto o ambiente quanto à capacidade intelectual dos sujeitos.

Como vivemos em uma sociedade, certamente estamos envoltos em paradigmas que determinam a construção de modelos pedagógicos que são desenvolvidos nas escolas e que servem como condutores das práticas de aprendizagem desenvolvidas no ambiente escolar. Essas práticas são mediadas por professores que desempenham suas funções a partir das habilidades que se construíram durante a formação inicial e se constroem ao longo do exercício profissional, aliadas às metodologias de ensino adotadas por cada professor. Portanto, como o processo de ensino-aprendizagem é uma habilidade desenvolvida pelo homem, logo podemos afirmar que é uma função social, pois "[...] o aprendizado humano pressupõe uma natureza social específica e um processo através do qual as crianças penetram na vida intelectual daqueles que as cercam" (VIGOTSKY, 1998, p. 115). Assim, é importante ressaltar que a aprendizagem do aluno depende em grande parte, dos modos e meios utilizados pelo professor para instrumentalizar o ensino.

Em se tratando de ensino-aprendizagem, voltamos nosso olhar aos professores em formação do Curso de Licenciatura em Matemática, na tentativa de compreender como esse processo ocorre, considerando que a disciplina Psicologia da Aprendizagem só é ofertada no $5^{\circ}$ semestre do curso, assim como as demais disciplinas pedagógicas que têm para si a responsabilidade de dar conta da formação didático-pedagógica dos professores em formação.

Quando entramos nas turmas do curso de Licenciatura em Matemática com disciplinas pedagógicas, vivenciamos duas situações bem antagônicas. De um lado, temos

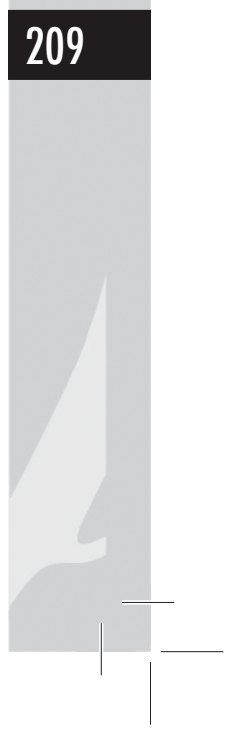




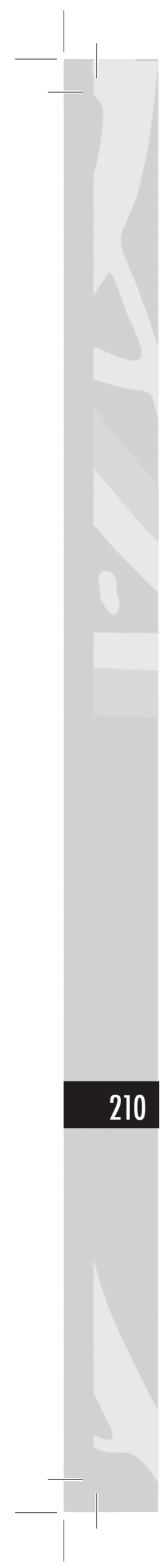

professores em formação que a princípio demonstram certa estranheza em relação à disciplina e, posteriormente, vão se envolvendo e passam a ter outra visão sobre as disciplinas da área pedagógica, pois que essas os aproximam das questões que serão vivenciadas por eles ao saírem do curso. De outro, temos professores em formação que consideram que essas disciplinas são dispensáveis para sua formação, pois esses não se veem em uma sala de aula ensinando crianças e adolescentes. Mesmo que o curso seja de licenciatura, existem alunos que não conseguem se ver como professor de Matemática e acabam considerando as disciplinas pedagógicas como complexas, preferindo as disciplinas que são específicas de área, pois consideram que, para ser professor de Matemática, é necessário apenas ter o domínio sobre os conteúdos matemáticos a serem ensinados.

Nesse pensar, consideramos que a formação didáticopedagógica ocorre dentro de uma fragilidade muito grande, pois não conseguimos compreender como professores em formação não conseguem ver as disciplinas pedagógicas como verdadeiras aliadas para o processo de formação da identidade do eu professor. Essa identidade ou não de ser professor pode se dar em momentos completamente distintos, pois, durante nossa prática docente, já tivemos a oportunidade de presenciar professores em formação que passaram a se identificar com a profissão professor a partir das leituras, discussões e envolvimento com as disciplinas pedagógicas. Assim como já presenciamos aqueles que, estando no último semestre do curso, ao se verem dentro da escola em disciplinas de Estágio Supervisionado, afirmam que não é isso que querem fazer e acabam desistindo do curso.

Portanto, considerando esses pressupostos, nosso olhar se direciona à percepção dos professores em formação em relação à disciplina Psicologia da Aprendizagem.

Eixo de Análise 1 - Percepção Conceitual dos professores em formação sobre a disciplina Psicologia da Aprendizagem.

Para falar em percepção necessariamente temos que fazer referências à função cerebral que atribui significado a estímulos 
sensoriais, que é a percepção, e é através dela que o indivíduo organiza e interpreta suas impressões sensoriais para atribuir significado ao seu meio. A percepção tem como percussores - Hermann Von Helmholtz, Gustav Theodor Fechner e Ernst Heinrich Weber, Wilhelm Wundt.

Para a Psicologia,

[...] a percepção é o processo ou resultado de se tornar consciente de objetos, relacionamentos e eventos por meio dos sentidos, que inclui atividades como reconhecer, observar e discriminar. Essas atividades permitem que os organismosse organizem e interpretem os estímulos recebidos em conhecimento significativo. (APA, 2010, p. 695)

$\mathrm{Na}$ Psicologia, o estudo da percepção tem uma importância fundamental para compreender o comportamento das pessoas que se baseia na interpretação que essas fazem da realidade e não na realidade em si, razão essa pela qual "[...] a percepção do mundo é diferente para cada um de nós, cada pessoa percebe um objeto ou uma situação de acordo com os aspectos que têm especial importância para si própria" (idem, ibidem, p. 696).

Porém, é importante considerar que a percepção que o indivíduo tem e/ou faz sobre algo está diretamente relacionada com as influências externas (próprias do ambiente) e internas (próprias do indivíduo) recebidas durante o processo perceptivo. Assim, vários são os fatores que podem influenciar a percepção, pois o processo de percepção tem início com a atenção que não é mais do que um processo de observação seletiva, ou seja, das observações por nós efetuadas (APA, 2010).

No desenvolvimento da percepção dos seres humanos, além dos fatores externos e internos, outros elementos estão presentes nesse processo como a visão e a audição. Além dos outros sentidos que têm a capacidade de fazer a percepção olfativa, gustativa, tátil, temporal, espacial e social (BARROS, 2009).

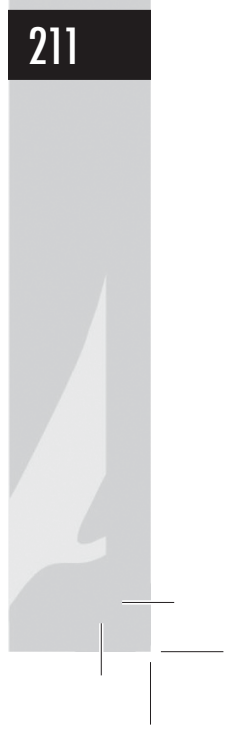


Um bom exemplo de percepção visual é o triângulo de Kanizsa que demonstra o princípio do fechamento.

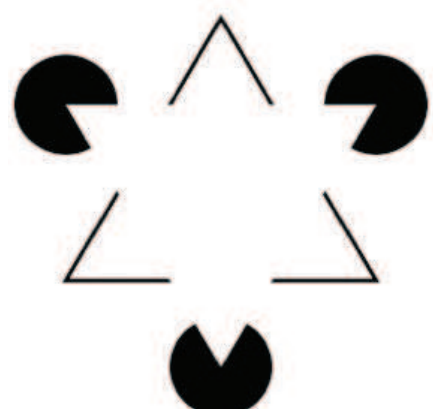

Tendemos a ver um triângulo branco sobreposto à figura, como uma figura completa e fechada, embora ele só seja sugerido por falhas nas demais formas que compõem a figura.

Quanto à percepção auditiva (BARROS, 2009), é feita dos fenômenos sonoros recebidos pelo ouvido. Em uma aula, muito da percepção auditiva é feita pelos sons emitidos pela fala do professor e de outros ruídos internos e externos que se misturam e, na maioria das vezes, acabam prejudicando tanto o professor ensinar quanto o aluno aprender.

A Percepção Social (BARROS, 2009) é um aspecto a ser considerado no processo de ensino-aprendizagem, pois a percepção de certos aspectos relacionados às características humanas pode ser constituída socialmente e sofre influências das questões de gênero, raça, nacionalidade, sexualidade e outras.

As três formas (visual, auditiva e social) de percepções acima apontadas são significativas na sala de aula, pois é da junção desses três elementos que a percepção se constrói, como podemos observar nos excertos a seguir apontados pelos professores em formação:

[...] na minha percepção a Psicologia da Aprendizagem é a disciplina que possibilita ao professor um melhoramento da sua prática pedagógica, uma vez que 
a mesma serve como auxilio para entender e visualizar os problemas que alguns alunos poderão enfrentar na absorção dos conteúdos ministrados dentro de sala. (Professores em Formação/Intensivo/2009)

[...] A Psicologia da Aprendizagem nos auxilia a compreender o processo de ensino/aprendizagem de diferentes maneiras: comportamento, sentimento, motivação, dificuldades de aprendizagem, entre outras, é essa a minha percepção da disciplina. (Professores em Formação/Extensivo/2010)

[...] percebo a disciplina como forma de compreender as fases e niveis de aprendizagem do aluno, permitindo, assim que o professor trabalhe os conteúdos de forma a considerar a fase e o nivel de aprendizagem que ele se encontra/apresenta. (Professores em Formação/ Extensivo/2009)

Os professores em formação do Curso de Licenciatura em Matemática desenvolveram suas percepções sobre a Psicologia da Aprendizagem durante o ensino da disciplina, considerando que a compreensão de dado conteúdo depende da clareza com que são colocados e do nível de compreensão dos alunos. Essas percepções apontam para uma visão de que a Psicologia da Aprendizagem permitirá a esses professores em formação, a compreensão dos níveis, fases e processos de ensinoaprendizagem dos alunos.

Na percepção desses sujeitos, a partir da compreensão desses processos, esses se tornarão profissionais mais capacitados para saber lidar com as situações surgidas em sala de aula, como podemos observar nos excertos a seguir:

[...] A Psicologia da Aprendizagem se refere a métodos de ensino, que poderemos adotar na sala de aula como professores no futuro. (Professores em Formação/ Extensivo/2010)

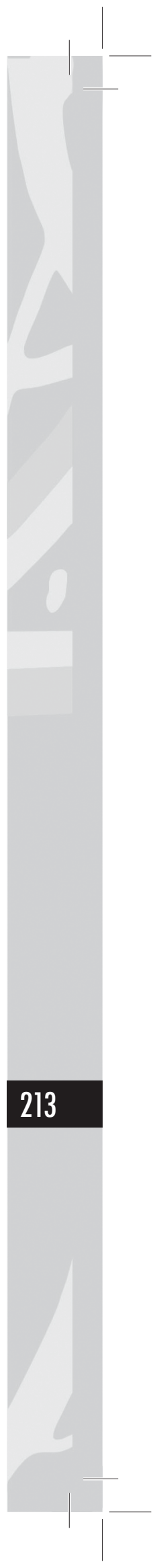


[...] A disciplinaéde extrema importância, pois contribui muito para capacitar o que seremos futuramente. (Professores em Formação/Extensivo/2009)

[...] A Psicologia da Aprendizagem nos dá noção de como saber lidar com algumas situações na sala de aula que vamos enfrentar como professores, [...] a disciplina auxilia os futuros professores a serem profissionais mais preparados e mais capacitados. (Professores em Formação/Intensivo/2009)

O que se observa é que esses sujeitos acreditam que os conteúdos trabalhados na disciplina podem contribuir para que, no momento em que estiverem desenvolvendo suas práticas docentes, esses possam lançar mão desses conhecimentos para auxiliá-los na resolução de situações surgidas na sala de aula, pois "[...] conforme a necessidade e a capacidade do organismo, os estímulos sensoriais são integrados, interpretados e tornamse significativos" (PRESTES, 2010, p. 56), ou seja, a partir da percepção significativa desses professores em formação em relação aos conteúdos aprendidos na disciplina, esses poderão fazer a interpretação da situação real vivenciada na sala de aula, pois a percepção se constitui como a principal fonte de aquisição de experiências humanas, tanto em espaços de convivência em determinado grupo social, quanto em contextos em que se vive com seus pares em ambiente de práticas, incluindo-se aqui as interações vivenciadas na sala de aula. E como falar de interação na sala de aula se não falarmos de relação/identidade de professores em formação.

Eixo de Análise 2 - A relação/identidade dos professores em formação com a disciplina Psicologia da Aprendizagem.

Dependendo de como nos relacionamos e/ou nos identificamos com o que ensinamos, com o como ensinamos e com para que ensinamos, os resultados podem ser favoráveis ou não para que a aprendizagem de determinados conteúdos sejam ou não apreendidos em qualquer nível de escolaridade, pois "[...] o conceito de identidade está formulado a partir das 
noções dos vínculos de integração espacial, temporal e do social do sentimento de identidade, os quais vão compor a dinâmica do funcionamento mental" (GRIMBERG, 1971, p. 106).

Para os professores em formação do curso de Licenciatura em Matemática essa identidade se constituiu a partir do entendimento do conteúdo e da compreensão desses sobre cada aspecto trabalhado, conforme podemos observar nos excertos a seguir.

[...] não tive dificuldades de me relacionar com a disciplina, ela é muito importante para minha formação, pois com ela aprendi como lidar com alunos de diferentes faixas etárias e com alunos que necessitam de um atendimento especial. (Professores em Formação/ Extensivo/2010)

[...] me identifiquei logo com a disciplina, pois tive a oportunidade de aprender que o professor precisa conhecer o tipo de aluno que tem e como saber lidar com cada indivíduo, então é que entra a participação da Psicologia que estuda o comportamento do ser humano. (Professores em Formação/Intensivo/2009)

[...] a disciplina me proporcionou um saber que vai me preparar para enfrentar e entender as dificuldades de ensino/aprendizagem dos alunos dentro e fora do ambiente escolar, isto ajudou a me identificar com a disciplina. (Professores em Formação/Extensivo/2009)

[...] A partir da minha relação/identidade com a disciplina vou poder desenvolver métodos de ensino para aplicar futuramente aos meus alunos $e$ melhorar o aprendizado. (Professores em Formação/ Extensivo/2009)

Observamos que os professores em formação não tiveram nenhuma dificuldade para estabelecer uma relação favorável com a disciplina e nem de se identificar com os 
conteúdos trabalhados. Observa-se ainda que esses sujeitos já conseguem fazer a associação dos conhecimentos desenvolvidos nas teorias estudadas a situações reais fazendo referência de uma futura utilização desses conhecimentos no desenvolvimento de suas práticas docentes de uma forma mais humanizada, pois consideram que a disciplina proporcionou o entendimento da necessidade de conhecer o aluno para poder compreender suas necessidades e limitações.

Para Grimberg (1971, p. 106),

[...] a identidade é a consciência do "eu individual" que o indivíduo tem como um ser de mundo. A identidade éo conhecimento por parte de cada indivíduo da condição de ser uma unidade pessoal, separada e distinta dos outros, permitindo-lhe reconhecer-se o mesmo a cada instante de sua evolução, correspondendo, no plano social, à resultante de todas as identificações prévias feitas até o momento considerado.

E considerando a afirmativa do autor, compreendemos que a identidade é própria de cada indivíduo e que essa se constitui da relação desse com as aproximações e/ou distanciamentos que esse indivíduo estabelece no meio temporal, espacial e social em que ele está inserido. No entanto, tivemos professores em formação que consideram que a disciplina está mais para a teoria do que para a prática, como podemos observar nos excertos a seguir.

[...] Há um grande embate de qualquer disciplina pedagógica com a Matemática. Embora a Psicologia da Aprendizagem nos capacite psicologicamente para situações vindouras, há um mundo lá fora que se diferencia de toda e qualquer teoria bem colocada na graduação. (Professores em Formação/Extensivo/2010)

[...] a minha relação com a Psicologia da Aprendizagem, apesar de considerar ser muito importante como auxiliar na resolução de problemas no ensino/ 
aprendizagem, ainda tenho que estreitar melhor meus conhecimentos com as teorias para obter melhores resultados. (Professores em Formação/Intensivo/2009)

Para uso dos conhecimentos teóricos em situações reais é necessário, antes de tudo, não só ter o domínio sobre determinada teoria, mas, principalmente, saber o quando, o onde e o como fazer uso dessas teorias para obter os resultados esperados, concordamos que "[...] há um mundo lá fora que se diferencia de toda e qualquer teoria [...]". Porém, é importante considerar que toda e qualquer teoria precede de uma prática que a antecedeu, pois assim como "[...] ninguém começa a ser educador numa certa terça-feira às quatro horas da tarde..." (FREIRE, 1991, p. 58), uma teoria não nasce sem que essa tenha sido fundamentada em bases que lhes deem sustentação. Assim, concordamos que é necessário não só estreitar relação com as teorias, mas também aproximar-se dessas para que a identidade necessária com essas teorias seja estabelecida, pois “[...] a gente se faz educador, a gente se forma como educador permanente, na prática e na reflexão sobre a prática" (idem, ibidem).

Eixo de Análise 3 - Distanciamentos e Aproximações entre a Psicologia da Aprendizagem e a Licenciatura em Matemática.

Falar em distanciamento (aqui compreendido como o ato ou efeito de distanciar ou distanciar-se de algo ou de alguma coisa) e aproximação (aqui entendida como uma representação inexata de algo ou de alguma coisa) é necessário primeiro nos colocarmos no lugar do outro e compreender como o ser humano se situa em espaços de convivência, pois essa relação é muito singular, cada indivíduo tem especificidades que lhes são próprias e que respondem pelas aproximações e/ou distanciamentos que esses estabelecem sobre uma determinada situação. Portanto, o distanciamento e a aproximação entre a disciplina Psicologia da Aprendizagem e a Licenciatura em Matemática foram conceituados a partir da compreensão dos professores em formação envolvidos neste estudo, como podemos observar nos excertos a seguir. 
[...] A Matemática se distancia porque tem uma fama histórica de que é uma disciplina difícil e praticamente impossivel de dominar. Mas ela também se aproxima da Psicologia da Aprendizagem porque a disciplina nos oferece ferramentas que ajudam a amenizar essa questão, porque com ela o professor passa a enxergar onde os alunos estão enfrentando dificuldades nos conteúdos ministrados dentro de classe. (Professores em formação/Extensivo/2009)

[...] a Matemática se distancia de todas as outras disciplinas porque ela é da área de exatas e as outras são de outra área, aí não tem como se aproximar. Mas quando a gente estuda a Psicologia a gente percebe que a Matemática devia se aproximar para a gente poder compreender como ensinar. (Professores em formação/ Extensivo/2010)

[...] como a Matemática tem como base a lógica e os números e a Psicologia tem o pensamento humano como uma de suas bases, aí está o distanciamento. (Professores em formação/Intensivo/2009)

Observa-se que o distanciamento aqui situado está no que culturalmente foi estabelecido em relação ao conhecimento matemático ser considerado da área "dura", não havendo espaço para que os conhecimentos de outras áreas sejam inseridos, o que consideramos como mito, pois a Matemática como uma ciência desenvolvida pelo homem e para o homem, o aspecto humano, ou seja, o conhecimento do próprio homem, não pode ser ignorada, pois segundo Chauí, (2000), "todas as ciências são humanas e resultam da atividade humana". Assim, por ser a Psicologia a ciência que estuda o comportamento humano e seus processos mentais, que passam pela sensação, emoção, percepção, aprendizagem etc., é fundamental que em processos de formação de professores que é uma atividade humana feita por humanos, os conhecimentos da Psicologia sejam inseridos 
para formar indivíduos capazes de compreender o homem e suas relações com o próprio homem e com o mundo.

Mesmo compreendendo a existência de um distanciamento, esses consideram que há certa aproximação, pois estão em processo de formação de professores, e a Psicologia contribui para o desenvolvimento desse processo, pois segundo Edward Thorndike (1874/1949) "o homem aprende por um processo de associação de ideias - da mais simples para a mais complexa", como podemos observar nos excertos a seguir:

[...] A Psicologia da Aprendizagem se aproxima porque ajuda os futuros professores licenciados em Matemática a compreender a dificuldade que o aluno apresenta em aprender e entender a Matemática, mas tem professor que não gosta de disciplinas pedagógicas, por isso ela se distancia da Matemática, eu penso que é assim. (Professores em formação/Intensivo/2009)

[...] Com certeza há uma aproximação muito grande, tendo em vista que estamos sendo formados professores. Então a disciplina não pode se distanciar da licenciatura. (Professores em formação/Extensivo/2009)

[...] há uma aproximação quando os conhecimentos da Psicologia são colocados na teoria. Mas quando essas teorias são colocadas na prática, nem sempre conseguimos observar essa aproximação, aí eu considero que há certo distanciamento. (Professores em formação/ Extensivo/2010)

\section{9}

O entendimento dos professores em formação sobre aproximação edistanciamentoentrea Psicologia da Aprendizagem e a Licenciatura em Matemática ainda está situado naquilo que a disciplina pode proporcionar em se tratando da compreensão do como saber ensinar. Esses não tiveram o entendimento de que a inserção do campo psicológico na área da educação tem como foco as relações que são estabelecidas pelos atores sociais que 
fazem a educação em torno das questões que se desenham no processo educativo. Mas, especificamente, trabalha com o ensino como ação criativa do educador na transmissão do conhecimento e com a aprendizagem como ação dos alunos na apreensão do conhecimento (PRESTES, 2010).

A Psicologia da Aprendizagem como disciplina que faz parte da preparação pedagógica deve alicerçar os professores em formação no sentido de estarem preparados não só para estabelecer conceitos e valores do que é ser professor, mas também para o desenvolvimento de suas práticas no saber fazer docente. E a Licenciatura em Matemática como meio condutor desse processo deve facilitar para que esses professores em formação sejam capazes de compreender como se desenvolve a dinâmica do binômio ensinar e aprender, sendo esta a ação primeira do profissional professor, pois "[...] quem ensina aprende ao ensinar, e quem aprende ensina ao aprender" (FREIRE, 1997, p. 25), num constante ir e vir dos saberes que se cruzam e se entrecruzam no ambiente da/na sala de aula.

Para Lopes (2002)

[...] ensinar consiste em reconhecer o lugar subjetivo de sujeito, se tomarmos a dimensão "psi" pela via psicanalítica, entendemos que o ensinar se sustenta num discurso, no que fala e no que é falado, ou seja, circunscrito na linguagem, na palavra, no diálogo imerso num espaço, num ponto. (p. 91)

Assim, de acordo com a afirmativa acima, a formação de professores em Matemática deve passar pelo lugar subjetivo de cada um, pois não dá para formar professor sem considerar as peculiaridades, singularidades e pluralidades de cada sujeito, que durante o processo formativo não se extinguem, nem se deixam atrás da porta. Elas estão lá e vão permanecer porque não são acessórios.

Portanto, é necessário que a escola além de adquirir:

[...] mobilidade, flexibilidade e identidade própria que decidam formas educativas, curriculares $e$ 
pedagógicas, não deve ser vista como fábrica ou oficina, como sugere a tradição funcionalista, mas o locus da preparação do sujeito social para a vida o que implica o desenvolvimento das subjetividades e da personalidade humana livre. (GOZO, 2000, p. 179).

$\mathrm{O}$ que nos leva a concluir que a Psicologia da Aprendizagem como disciplina está situada no campo relacional entre o aprender e o ensinar, "[...] como espaço de possibilidades interativas, de trocas interpessoais onde a ação educativa deixa de exercer o controle e passa a ser uma atividade que conduz ao crescimento e à flexibilidade para mudanças dos agentes escolares" (PRESTES, 2010, p. 39).

Assim, durante as aulas de Psicologia da Aprendizagem nas três turmas (2008, 2009 e 2010) do Curso de Licenciatura em Matemática que serviram de cenário para a realização deste estudo, tivemos alguns episódios que foram marcantes, afinal de contas não é comum esses sujeitos se verem numa sala de aula envoltos com o que conversam, concordam, discordam e se contrapõe teóricos como - Sigmund Freud, Jean Piaget, Lev Vygotsky, Henri Wallon, entre outros que estiveram presentes em nossas aulas.

Para os professores em formação, essas pessoas de nomes difíceis de serem pronunciados são completamente estranhas, pois esses estavam mais familiarizados com Baruck, Durval, Guidorizzi, Helon, nomes comuns durante os primeiros anos do curso. E tentar entender as teorias da aprendizagem que foram/são defendidas pelos teóricos da Psicologia da Aprendizagem, não é tarefa fácil, eu diria até que é assustador para alguns alunos que não conseguiam compreender determinados conceitos do campo da Psicologia. No entanto, passado o primeiro impacto e na medida em que as teorias iam sendo estudadas, observávamos que alguns alunos ficavam encantados com o que viam, ouviam e liam sobre as teorias. Outros consideravam esses teóricos como loucos por pensarem o comportamento humano a partir dessas teorias. Esse encantamento levou alguns professores em formação a desenvolverem seus trabalhos de conclusão do curso - TCC, dentro da Educação

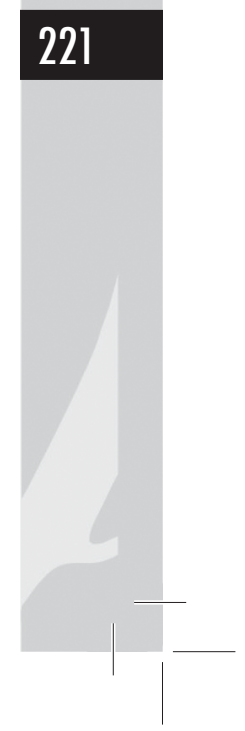


Matemática, na perspectiva de investigar e compreender as dificuldades de aprendizagem da Matemática, fortemente presentes nos espaços de aprendizagem, preocupação essa que já faz parte da vida desses futuros professores.

Essa preocupação nos leva a concluir que necessitamos formar pessoas, sejam em cursos de Licenciatura em Matemática ou em qualquer outra área do conhecimento, que saibam usar as teorias e/ou informações advindas dessas, para realizar mudanças em si mesmas e no outro, que consigam pensar a vida como um desafio a ser vencido, pois "[...] viver tem o significado de preservar e de modificar, paradoxo imposto pela força da bio(vida)logia do ser em transação permanente com as imposições do ambiente, resultantes da convivência" (PRETTE, 2001, p. 222).

Assim, considerando a aproximação e o distanciamento existente na relação da Psicologia da Aprendizagem com a Licenciatura em Matemática, apontados pelos professores em formação, considerando ainda que tanto a aproximação quanto o distanciamento ocorrem em determinadas situações e em determinados contextos, independentemente de nossa vontade, cada pessoa também percebe e desenvolve atitudes e comportamentos individualizados em relação a seu ambiente físico e social, tanto por aproximação como por distanciamento. Portanto, quando desenvolvemos a ação humana de formar professores devemos sempre ter a preocupação de estar nos perguntando: Quem, Como e Para que estamos formando? Para que escola? Para que sociedade?

\section{REFERÊNCIAS}

APA - Associação da Psicologia da Aprendizagem. Rio de Janeiro. 2010.

BARROS, José D’Assunção. A construção social da cor. Petrópolis: Vozes, 2009. 
CARVALHO, Vilson Sérgio de. Raízes da Ecologia Social: O Percurso Interdisciplinar de uma Ciência em Construção. Rio de Janeiro: EICOS/IP/UFRJ, 2005.

CHAUÍ, Marilena. Convite à Filosofia. São Paulo: Ática, 2000.

FREIRE, Paulo. A educação na cidade. São Paulo: Cortez, 1991.

Pedagogia da Autonomia: saberes necessários à prática educativa. São Paulo: Paz e Terra, 1997.

GOZO, AparecidoTheodoro. Gestão da organização a partir dos talentos. In: . Olhar do Professor. Ponta Grossa: Universidade Estadual de Ponta Grossa, 2000.

GRIMBERG, León; GRIMBERG, Rebeca. Identidad y crisis. Buenos Aires: Kargieman, 1971.

KUPFER, Maria Cristina. Freud e a educação. São Paulo: Scipione, 1989.

LINCOLN, Y. S.; GUBA, E. G. Naturalistic inquiry. Londres: Sage, 1985.

LOPES, Ensinar e Aprender. Revista Psicanalise Infância Educação, São Paulo, Linear B. USP, 2002.

MORAES, Roque. UMA TEMPESTADE DE LUZ: a compreensão possibilitada pela análise textual discursiva. Ciência \& Educação, v. 9, n. 2, p. 191-211, 2003.

PRESTES, Irene Carmem Picone. MORO, Catarina de Sousa. Psicologia e Educação. Curitiba, PR: IESDE Brasil S.A., 2010.

PRETTE, Almir. Psicologia das relações interpessoais: vivencias para o trabalho em grupo. Petrópolis: Vozes, 2001.

VIGOTSKY, Lev S. Formação social da mente. São Paulo: Martins Fontes, 1998. 